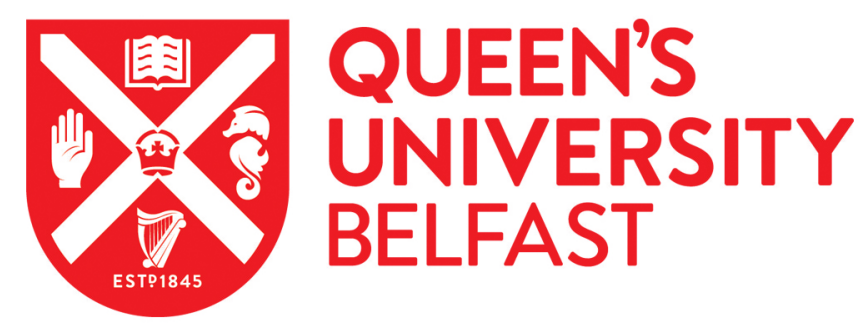

\title{
Suitability of alkali activated slag/fly ash (AA-GGBS/FA) concretes for chloride environments: Characterisation based on mix design and compliance testing
}

Bondar, D., Basheer, M., \& Nanukuttan, S. (2019). Suitability of alkali activated slag/fly ash (AA-GGBS/FA) concretes for chloride environments: Characterisation based on mix design and compliance testing. Construction and Building Materials, 216, 612-621. https://doi.org/10.1016/j.conbuildmat.2019.05.043

Published in:

Construction and Building Materials

Document Version:

Peer reviewed version

Queen's University Belfast - Research Portal:

Link to publication record in Queen's University Belfast Research Portal

\section{Publisher rights}

Copyright 2019 Elsevier.

This manuscript is distributed under a Creative Commons Attribution-NonCommercial-NoDerivs License

(https://creativecommons.org/licenses/by-nc-nd/4.0/), which permits distribution and reproduction for non-commercial purposes, provided the author and source are cited.

\section{General rights}

Copyright for the publications made accessible via the Queen's University Belfast Research Portal is retained by the author(s) and / or other copyright owners and it is a condition of accessing these publications that users recognise and abide by the legal requirements associated with these rights.

Take down policy

The Research Portal is Queen's institutional repository that provides access to Queen's research output. Every effort has been made to ensure that content in the Research Portal does not infringe any person's rights, or applicable UK laws. If you discover content in the

Research Portal that you believe breaches copyright or violates any law, please contact openaccess@qub.ac.uk. 


\title{
Suitability of alkali activated slag/fly ash (AA-GGBS/FA) concretes for chloride environments: Characterisation based on mix design and compliance testing
}

\author{
Dali Bondar ${ }^{1}$, Marios Soutsos ${ }^{1}$, Muhammed Basheer ${ }^{2}$, Sreejith Nanukuttan ${ }^{1}$ \\ ${ }^{1}$ School of Natural and Built Environment, Queen's University Belfast, BT9 5AG, UK \\ ${ }^{2}$ School of Civil Engineering, University of Leeds, Leeds, LS2 9 JT, UK \\ Email: D.Bondar@qub.ac.uk,m.soutsos@qub.ac.uk,p.a.m.basheer@leeds.ac.uk, \\ s.nanukuttan@qub.ac.uk
}

\begin{abstract}
Ground granulated blast furnace slag (GGBS) and fly ash are two of the most common industrial byproducts used as precursors in an alkali activated material (AAM). Alkali-activated systems with fly ash as the sole precursor often require elevated temperature curing, while if made with GGBS alone can lead to flash setting, low workability and high degree of drying shrinkage. This article presents data from a range of GGBS/Fly Ash blends designed to avoid elevated temperature curing whilst achieving desirable fresh properties. Further, the suitability of such blended concrete for their use in chloride environments is outlined with the help of diffusivity testing and binding assessment. The results show that while attractive engineering properties can be achieved, chloride ingress in the AA-GGBS/FA concretes studied here with $\geq 20 \%$ fly ash is moderate to high. Reduction in $\mathrm{pH}$ resulting from the long term exposure to chloride solution also affected the ability of the binder to chemically or physically binding chlorides.
\end{abstract}

Keywords: alkali activated slag/fly ash (AA-GGBS/FA) concretes, workability, compressive strength, bulk resistivity, chloride diffusion coefficient, chloride binding

\section{Introduction}

Alkali Activated Materials (AAMs) have been under consideration as an alternative binder system since 1895 [1]. The main limitations facing the commercial adoption of these binders are the challenges in controlling engineering properties when using intrinsically variable waste-derived precursors, and the lack of field performance data, especially in extreme environments. GGBS and fly ash are the major by-products used as precursors for making these types of binders. Previous investigations show that alkali-activated high calcium systems such as alkali activated slag (AAS) concretes usually set rapidly, can have low workability, and sometimes also a high degree of drying shrinkage compared to Portland cement (PC) based systems, and all of these are known to affect durability properties [2-6]. Low calcium alkali activated systems, on the other hand, can exhibit high workability and a lower shrinkage than PC systems [7], but need elevated temperatures for curing and hardening. Chi and Huang [8] studied the behaviour of the binder products and properties of AA-GGBS/FA blended mortars and concluded that better properties, compared to $\mathrm{PC}$, were obtained in terms of compressive strength, flexural strength and water absorption. Abdalqader et al. [9] found that the highest strength of AA-GGBS/FA obtained was with a paste mix consisting of GGBS: fly ash in a 3:1 ratio. Gao et al. reported that concrete with a higher GGBS/fly ash ratio exhibit lower porosity [9-10]. However, despite having been aware of this material's potential for over a century, there is still relatively little known about the durability of AAMs, especially the resistance to chloride ingress and the binding behaviour. It was reported by Roy et al. that the advantageous properties of AA-GGBS/FA are their high early strength, rapid hardening and high ultimate strength, low heat of hydration, and resistance to effects resulting from the chemical attack. Diffusion coefficients of $50 \times 10^{-15}$ and $5 \times 10^{-15} \mathrm{~m}^{2} / \mathrm{s}$ were reported for the blended OPC and GGBS paste activated with $\mathrm{NaOH}$, with 0 and $100 \%$ GGBS replacement [11].

In this investigation, blended binder systems were used as they provide control of properties such as setting time, workability, shrinkage, strength and durability compared to those based on $100 \%$ fly ash 
or GGBS. An experimental programme was developed to study the workability, strength development and resistance to chloride ingress for a range of AA-GGBS/FA concrete mixes that do not require high temperature curing. Fresh properties, compressive strength at different ages, bulk resistivity, long term chloride diffusion and binding behaviour were determined and reported for various AA-GGBS/FA concretes.

\section{Experimental details}

\subsection{Materials}

The primary raw materials used in this study were GGBS and low-CaO fly ash, which were provided by ECOCEM - Ireland and Power Minerals Ltd, UK, respectively. The chemical and physical properties are presented in Tables 1 and 2. GGBS and fly ash were blended in 80/20, 60/40, 40/60 and 20/80 mass proportions, to be activated and used as a binder.

Sodium hydroxide $(\mathrm{NaOH})$ powder or pellets were dissolved in water to produce the alkaline solutions. The chemical composition of the sodium silicate solution was $15.5 \%$ sodium oxide $\left(\mathrm{Na}_{2} \mathrm{O}\right), 30.5 \%$ silicon oxide $\left(\mathrm{SiO}_{2}\right)$ and $54 \%$ water. In this study, the percentage $\mathrm{Na}_{2} \mathrm{O} \%$ in the paste $\left(\mathrm{Na}_{2} \mathrm{O} \%\right)$ was selected to be 6 and $8 \%$ by powder (GGBS and fly ash) weight, and the silicate modulus (molar ratio $\mathrm{SiO}_{2} / \mathrm{Na}_{2} \mathrm{O}$ ) was varied from $0.45,1.0$ and 1.25 , by blending sodium silicate and sodium hydroxide.

The aggregates used in this study were crushed basalt from local sources in Northern Ireland and comprised of $16.5 \mathrm{~mm}$ and $10 \mathrm{~mm}$ crushed coarse aggregates, and $4 \mathrm{~mm}$ sand. These were combined in a ratio of 48:12:40 to get the maximum packing density in (AA-GGBS/FA) concrete mixes. The bulk specific gravity and water absorption of these materials were measured based on BS EN 1097-1 and are presented in Table 3. Potable tap water (i.e. drinking water quality) was used to make the concrete mixes.

\subsection{Mix details, casting procedure and test specimens}

Sixteen (AA-GGBS/FA) concrete mixes were studied with different GGBS/fly ash content, water-tobinder, the percentage of alkali and the $\mathrm{SiO}_{2} / \mathrm{Na}_{2} \mathrm{O}$ ratio (silica modulus, Ms). The details of the different mixes and their initial properties are presented in Table 4 . The total binder content, which is the sum of GGBS, fly ash and solid component of the WG, was kept constant at $425 \mathrm{~kg} / \mathrm{m}^{3}$ for all mixes and the water content in the water-glass (WG) was taken into account while determining the mixing water. For increasing proportions of the fly ash, the $\mathrm{W} / \mathrm{B}$ for mixtures was reduced while the paste content of the mixtures was kept constant.

\section{Mixing}

Blended cements were prepared by dry-mixing GGBS and fly ash in required proportions in a bench top food mixer to get a homogeneous blended powder. Crushed basalt aggregates and sand were dry mixed together in a laboratory pan-mixer for one minute. After adding the blended GGBS and fly ash powder, mixing continued for another 2 minutes. The sodium hydroxide solution was then added, and after 2 minutes of further mixing, sodium silicate solution was added and mixing continued for a further minute. The details of the different mixes and their essential properties are presented in Table 4.

\section{Casting and curing of the specimens}

Fresh properties of concrete were measured according to BS EN 12350 [12]. From each concrete mix, nine $100 \mathrm{~mm}$ cubes, and three $100 \times 200 \mathrm{~mm}$ cylinders, were cast for the determination of compressive strength in accordance with BS EN 12390 [13] at 2, 28 and 90 days of age, with three replicate samples tested per age, bulk resistivity and chloride diffusion coefficient according to Nordtest NT Build 443 [14]. The concrete specimens were cast in three layers and compacted on a vibrating table. After casting, all the specimens (still in the mould) were covered with plastic sheets and left in the casting room for 
$24 \mathrm{~h}$. They were demoulded and kept in sealed plastic zip bags until the test date. The storage room was maintained at $23^{\circ} \mathrm{C} \& 65 \% \mathrm{RH}$.

\subsection{Testing procedures}

Chloride transport through AA-GGBS/FA concretes was assessed using a non-steady state chloride diffusion test, Nordtest NT Build 443 [14]. One day before the test age of 91 days, the 100x200 mm concrete cylinders were cut to four slices of diameter $100 \mathrm{~mm}$ with a thickness of $50 \mathrm{~mm}$ per mix. A slice with a thickness of $50 \mathrm{~mm}$ from the cast surface (trowel finished face) was considered for measuring bulk resistivity, and the rest were kept for carrying out the chloride diffusion test. The vacuum saturation regime specified in the standard was used to precondition the slices so that the chloride flow is predominantly diffusive, and initial sorption or capillary forces are negligible. The vacuum was applied to remove air for three hours and released afterward. Samples were wrapped in hessian saturated in deionised water to prevent leaching of ions, and placed in the container. The weight of the sample was noted after an hour $\left(\mathrm{W}_{1}\right)$ and then vacuum was applied, followed by further saturation. Weight was checked again $\left(\mathrm{W}_{2}\right)$. Usually after 6 hours, when $\mathrm{W}_{\mathrm{i}}-\mathrm{W}_{(\mathrm{i}-1)}$ was less than $0.1 \%$, the samples were considered fully saturated; if not, saturation was continued until this criterion was met. After conditioning to a surface-dry condition, an epoxy resin was applied onto the surfaces of the specimens in three layers except for the exposure face (saw cut face). When the epoxy coating was dry, the cores were immersed in a $\mathrm{NaCl}$ solution of concentration $165 \mathrm{~g} / \mathrm{L}(\sim 2.82 \mathrm{M})$ for six months. After immersion, two cores for each mix were profile ground to obtain concrete dust from different depths up to a depth was determined for each sample by spraying a $0.1 \mathrm{~N}$ AgNO3 solution on the third freshly broken concrete sample. These depths were measured from the exposed surface. The total chloride content of the dust samples was determined in accordance with the recommendations of RILEM TC 178-TMC [15] using a pre-calibrated potentiometric titration method. The concrete dust was dissolved in deionised water in accordance with RILEM TC 178-TMC recommendations, considering 3-5 min digestion [16] to measure the $\mathrm{pH}$ value of the suspension, and for the determination of water soluble chlorides. Chloride diffusivity and the surface chloride content were determined by using curve fitting to the error function solution of Fick's second law of diffusion, as described in NT BUILD 443 [14].

\section{Results and discussions}

The following sections discuss the slump, flow and air content, compressive strength, chloride diffusivity, and chloride binding capacity of AA-GGBS/FA concretes. The histograms categorize the results for groups of concretes with different ratios of GGBS/FA and the contours graph are a good map for designing AA-GGBS/FA concretes mixes based on GGBS/FA ratio and activator parameters $\left(\mathrm{Na}_{2} \mathrm{O} \% * \mathrm{Ms}\right)$.

\subsection{Slump, flow and air content}

The purpose of this testing programme was to demonstrate the range of slump values that AAGGBS/FA concretes is capable of producing, and the changes to the governing variables that are necessary to achieve high slump with low air content of the GGBS/FA mixes to have better mixes for durability. The slump and flow results of the concretes are presented in Figures 1 and 2. The slump values of the concretes show that all the mixes had a slump value greater than $120 \mathrm{~mm}$. It can be observed that although W/B was adjusted based on the proportion of the fly ash in the system, increasing the fly ash in the blend increased the workability, and the maximum workability was achieved for mix with the maximum fly ash content due to its spherical shape. The literature shows that increasing the sodium oxide content results in increased workability, reduced setting times and higher compressive strength. However, high concentrations resulted in a loose structure in sodium hydroxide activated samples because of the excess water is being retained in the system before forming a monolithic hydrated structure $[18,19]$. For mixes with the same GGBS to fly ash content and water to binder ratios, comparing mixes 1, 5, 9 and 13 and mixes $4,8,12$ and 16 respectively, the slump values of the AA- 
GGBS/FA concretes with the same Ms ratio increased with an increase of $\mathrm{Na}_{2} \mathrm{O} \%$. The slump values also increased with the increase of Ms which can be seen by comparing odd and even mixes (e.g. mix no. 1 against 2, 3 against 4 ) in the two groups with two different $\mathrm{Na}_{2} \mathrm{O} \%$ and the same ratios of GGBS to fly ash.

As is evident from Fig. 1, the AA-GGBS/FA concretes can be designed for S3, S4 and S5 slump ranges. Thus, all the mixes meeting the minimum slump requirement for their use in chloride environments, such as S2 specified in BS8500-1:2015 for different exposure of marine environments [17].

The contour map graphs in Figure 3 (a) and (b) shows the results of slump and flow test against GGBS/FA ratio and a function of activator parameters or $\left(\mathrm{Na}_{2} \mathrm{O} \% * \mathrm{Ms}\right)$ values for different mixes with same paste content. $\left(\mathrm{Na}_{2} \mathrm{O} \% * \mathrm{Ms}\right)$ is the ratio of the $\mathrm{SiO}_{2}$ content of the activator to the total cementitious materials content for mixes. It is depicted from both figures that increasing the GGBS/FA ratio, decreases the workability of mixes for GGBS/FA $<0.67$ and GGBS/FA $>1.5$ while increases that for $0.67<\mathrm{GGBS} / \mathrm{FA}<1.5$. The maximum workability of mixes happens when $1.5<\mathrm{GGBS} / \mathrm{FA}<2.5$ and $\left(\mathrm{Na}_{2} \mathrm{O} \% * \mathrm{Ms}\right)$ values are less than 7.5. It is also evident from these figures that workability increased when $\left(\mathrm{Na}_{2} \mathrm{O} \% * \mathrm{Ms}\right)$ was increased which can be due to the disparity of silica in solution form.

The air content of the GGBS/FA mixes are presented in Figure 4 and Figure 5 and they show the contour graph for air content in fresh mixes of AA-GGBS/FA concretes against GGBS/FA ratio and $\left(\mathrm{Na}_{2} \mathrm{O} \% * \mathrm{Ms}\right)$ values. The lowest air content was measured for mixes with a GGBS/fly ash ratio of $60 / 40$ while the highest was for 20/80 (except mix 15) while considering the map analysis there are two ideal islands which shows the minimum air content in the fresh AA-GGBS/FA concretes. These two islands happen when $0.6<\mathrm{GGBS} / \mathrm{FA}<1.0$ or $1.0<\mathrm{GGBS} / \mathrm{FA}<2.25$ and the $\left(\mathrm{Na}_{2} \mathrm{O} \% * \mathrm{Ms}\right)$ for mixes is more than $6.75 \%$ and less than $4.25 \%$, respectively which are recommendable to have workable AAGGBS/FA concrete with low air content. Figure 4 also shows in the mixes made with a higher alkali percentage, the air content is lower (comparing Mixes 1, 5 and 13 to Mixes 4, 8 and 16, respectively) and higher Ms for mixes has had no major effect, especially for mixes with higher alkaline content (comparing Mixes 3 to 4 or 7 to 8). However higher silica content in the activator was more effective when the fly ash proportion increased in the blend, and this causes higher air content when using higher silica content (comparing Mixes 15 to 16) which means silica do not let air to be pushed out from fresh concrete.

\subsection{Compressive strength}

Figure 6 shows the compressive strengths of AA-GGBS/FA concrete mixes at 2, 28 and 90 days. From the results, it can be stated that: (1) the first three groups had more than $20 \mathrm{MPa}$ after 2 days and more than $50 \mathrm{MPa}$ after 28 days curing and 28 day strength is $80-90 \%$ of the 91 day strength, offering insight into the short and long term microstructural development in such binders, (2) as is expected, the more fly ash in the system, the lower is the early age and long term strength, (3) an increase in $\mathrm{Na}_{2} \mathrm{O} \%$ and Ms generally increases the compressive strength of AA-GGBS/FA concretes, which agrees with the results reported by others. The last one is due to more N-A-S-H (sodium alumina silicate hydrate) reaction product being generated, based on the increase of $\mathrm{Na}_{2} \mathrm{O} \%$, and more C-A-S-H (calcium alumina silicate hydrate) reaction product being produced, based on the increase of $\mathrm{SiO}_{2}$ content. Silica modulus of 0.45 will drop down the strength for $\mathrm{Na}_{2} \mathrm{O} \%$ of $8 \%$ and this can be because of low silica content in the activator to make the gel formation. The activated GGBS/fly ash concretes with Ms of 1.0 up to 1.25 generally obtained the highest compressive strength (see Figure 6), which also has a good agreement with the literature and shows that the activated GGBS/fly ash with Ms of around 1.0 obtains the best hydration. From the 28day compressive strengths, Table 4 and Figure 6 both show that except mixes no. $7(1.5-8 \%-0.45), 11(0.67-8 \%-0.45)$ and 13 to 16 with GGBS/FA=0.25, all achieved the required strength for the EN206 exposure classes XS3 and XD3 which is equivalent to an average strength $\geq 56.99 \mathrm{MPa}$ (calculated as $45+1.48(8.1) \mathrm{MPa}$; where 8.1 is the standard deviation of the test results). However, mixes $7(1.5-8 \%-0.45), 11(0.67-8 \%-0.45)$ and $16(0.25-8 \%-1.0)$ met the strength 
requirement of $48.99(=37+1.48(8.1)) \mathrm{MPa}$ for the exposure classes XS1, XD1 and XD2. Although it was evident that the strength requirement and w/b will not comply with BS 8500-1:2015 norms, the intention of including the mixes were to assess their performance against $\mathrm{Cl}^{-}$ingress.

Figure 7 (a) to 7 (c) presents the contour map of 2, 28 and 90 days compressive strength against GGBS/FA ratio and $\left(\mathrm{Na}_{2} \mathrm{O} \% * \mathrm{Ms}\right)$ values. In general, there is an increase in the 2, 28-days compressive strength values with increase in the $\mathrm{SiO}_{2}$ content of the activator to the total cementitious materials content. However, when the $\mathrm{SiO}_{2}$ content of the activator reach $6.5 \%$ and $7.5 \%$ of the total cementitious materials content respectively the reverse trend is started. 90-days compressive strength does not change significantly for GGBS/FA ratio $>1.5$ and $\left(\mathrm{Na}_{2} \mathrm{O} \% * \mathrm{Ms}\right)>6$.

\subsection{Bulk electrical resistivity}

Electrical resistivity can evaluate the microstructure of concrete and be related to the pore structure and conductivity of the pore solution to predict the diffusion coefficients of chloride ions. The test set-up for measuring bulk resistivity is shown in Figure 8. Figure 9 depicts the average bulk electrical resistivity for different AA-GGBS/FA concrete mixes. Higher resistivity could be attributed to the denser structure with low connected porosity and/or less conductivity of the binder matrix and such mixes will be expected to be superior in resisting ionic (chloride) flow. Higher GGBS content in AAGGBS/FA concretes resulted in higher bulk resistivity, while mixes with higher alkali content show higher bulk resistivity when GGBS dominates the blend. Furthermore, bulk electrical resistivity decreases for mixes made with higher silica modulus (except Mixes 3 and 4), whereas the bulk resistivity seems to be a maximum at $\mathrm{Na}_{2} \mathrm{O}=8 \%$ and $\mathrm{Ms}=1.0$ when GGBS/FA=80/20. This may be related to the alkali content which is required to produce maximum reaction products and gives the confidence for designing the concretes for strength and durability.

Figure 10 shows the contour graph of bulk electrical resistivity for different mixes against GGBS/FA ratio and $\left(\mathrm{Na}_{2} \mathrm{O} \% * \mathrm{Ms}\right)$ values. It is depicted from Figure 10 that for mixes with GGBS/FA $<0.67$ the $\mathrm{SiO}_{2}$ content of the activator has minimal influence on bulk resistivity and the resistivity does not change for $\left(\mathrm{Na}_{2} \mathrm{O} \% * \mathrm{Ms}\right)<6.25 \%$. This can show that for GGBS to fly ash less than 0.67 and $\left(\mathrm{Na}_{2} \mathrm{O} \% * \mathrm{Ms}\right)<6.25 \%$ pore structure dominates the conductivity of the system which is not dependent on the activator specification. Whereas for $\left(\mathrm{Na}_{2} \mathrm{O} \% * \mathrm{Ms}\right)>6.25 \%$ the resistivity decreases with increasing of the $\left(\mathrm{Na}_{2} \mathrm{O} \% * \mathrm{Ms}\right)$ which shows that pore solution domination and higher conductivity because of free ions in the binder matrix reduce the resistivity. For mixes with same $\left(\mathrm{Na}_{2} \mathrm{O} \% * \mathrm{Ms}\right)$ the bulk resistivity increases with increasing of GGBS to fly ash ratio for GGBS/FA $<0.67$ and GGBS/FA $>1.5$. This shows the effect of having a denser structure and is because of higher GGBS content in the binder matrix of mixes. While for $0.67<\mathrm{GGBS} / \mathrm{FA}<1.5$ and $\left(\mathrm{Na}_{2} \mathrm{O} \% * \mathrm{Ms}\right)<7.5$ pore solution domination causes the reduction of resistivity and higher conductivity because of free ions in the pore solution. This can show the range of $\left(\mathrm{Na}_{2} \mathrm{O} \% * \mathrm{Ms}\right)$ which is suitable for activation corresponding to different GGBS to fly ash ratio and should be more than 7.5 for $0.67<\mathrm{GGBS} / \mathrm{FA}<1.5$.

\subsection{Chloride diffusion}

Concrete specimens were prepared by coating all surfaces except the top face and were placed in sodium chloride solution in an airtight container for the diffusion test as per NT Build 443. The typical test set up is as shown in Figure 11.

Figure 12 presents the average chloride diffusion depth $\left(\mathrm{X}_{\mathrm{d}}\right)$ and the non-steady state chloride diffusion coefficients $\left(\mathrm{D}_{\text {nssd }}\right)$ for all the mixes. As shown in Figure 12 the chloride diffusion depth of AAGGBS/FA concretes was from $13 \mathrm{~mm}$ for mixes 2(6\%-1.25), 3(8\%-0.45), 4(8\%-1.0) with GGBS/FA=80/20 to $40 \mathrm{~mm}$ for mixes $13(6 \%-1.0)$ and $14(6 \%-1.25)$ with GGBS/FA=20/80.

The diffusion coefficient for AA-GGBS/FA concretes ranged between $1.05^{*} 10^{-12} \mathrm{~m}^{2} / \mathrm{s}$ [mix3 (8\%-0.45)] for GGBS/FA=80/20 and $126.51 * 10^{-12} \mathrm{~m}^{2} / \mathrm{s}$ [mix 14 (6\%-1.25)] for GGBS/FA=20/80. It can be seen that 
$D_{\text {nssd }}$ for all concretes with the exception of GGBS to Fly Ash ratio of 80/20, was moderate to high. This is in line with findings reported by Mundra et al. [20]. The non-steady diffusion coefficient, $\mathrm{D}_{\text {nssd, }}$ of the AA-GGBS/FA concretes was found to be influenced by the fly ash content, $\mathrm{Na}_{2} \mathrm{O} \%$ and $\mathrm{Ms}$ (at mixes with low alkali content). The $\mathrm{D}_{\text {nssd }}$ values were high for concretes with higher fly ash content, which is due to the influence of larger pore size and the better pore connectivity.

The third group of data with an average $D_{\text {nssd }}$ of $13.56\left(x^{-12} \mathrm{~m}^{2} / \mathrm{s}\right)$, is approximately a magnitude higher than 80/20 Slag/FA blends and three times higher than 60/40 blends. This can be due to the higher chloride absorption in the third group which has more fly ash in the system. Activated fly ash has been shown to have zeolite formation with better initial surface absorption (physical chloride binding) than activated slag [21]. Surface absorption is stated as the main reason responsible for around $90 \%$ of the total chloride uptake [22].

Figure 13 shows the contour map of $\mathrm{D}_{\text {nssd }}$ of different AA-GGBS/FA concrete mixes against GGBS/FA ratio and $\left(\mathrm{Na}_{2} \mathrm{O} \% * \mathrm{Ms}\right)$ values. $\mathrm{D}_{\text {nssd }}$ of AA-GGBS/FA concrete mixes does not change significantly with the increase of the ratio of the $\mathrm{SiO}_{2}$ content of the activator to the total cementitious materials content for GGBS/FA ratio $<1.0$ and $\left(\mathrm{Na}_{2} \mathrm{O} \% * \mathrm{Ms}\right)<6.0$. Furthermore $\left(\mathrm{Na}_{2} \mathrm{O} \% * \mathrm{Ms}\right)=6.0$ is an extreme point and at which $\mathrm{D}_{\text {nssd }}$ of AA-GGBS/FA concrete mixes for values less than 6.0 is decreasing while for values more than 6.0 is increasing. The plaid area in Figure 13 shows the limits of designing AAGGBS/FA concrete mixes suitable for chloride exposure environments if reinforcing steel is preferred.

\subsection{Chloride binding in AA-GGBS/FA concrete}

There is limited information available on the chloride binding of AA-GGBS/FA concrete in literature. What is possible is that the available CSH and aluminate phases (C-(N)-A-S-H or two layered double hydroxides) in activated GGBS contribute to the physical and chemical binding reactions [22, 23]. For activated systems with FA, it has been postulated that binding gel surfaces will increase with the inclusion of FA [24] and therefore will lead to higher physical adsorption of chloride ions [25] compared to C-A-S-H only system. Binding behavior of different alkali activated slag (AAS) concretes were reported in the previous article by the authors [26]. and it was shown that AAS concrete performed significantly better than conventional $\mathrm{PC}$ based binders in terms of restricting $\mathrm{Cl}^{-}$transport. Following the same procedure, the total and water-soluble chloride concentration of the concrete dust removed for chloride diffusion test in section 3.3 was determined for mixes 13-16.

In a typical PC based system, the total $\mathrm{Cl}^{-}$will be composed of both bound and free chlorides, and free chloride is often represented by the water-soluble fraction which may also contain a proportion of the adhered $\mathrm{Cl}^{-}$physically bound to the cement phases. It is also known that $\mathrm{pH}$ reduction can release the $\mathrm{Cl}^{-}$otherwise bound to Friedel's salt [25] in a PC based systems. Ismail et al. [25] reported that Friedel salt was not detected in their study of both GGBS and GGBS/FA activated systems and therefore suggested that majority or all of the bound chlorides will be physically adsorbed to the gel. The key aspects noticeable from the results presented in figures 14 a-d are:

(1) the $\mathrm{pH}$ values are $\leq 11$ for most depths (or all depths). The inclusion of FA to GGBS based activated system is known to increase alkali binding (as calcium content decrease) and therefore will result in $\mathrm{pH}$ reduction in pore solution [27]. In such systems, salt $(\mathrm{NaCl})$ precipitation was also observed in the pores and was suggested to have occurred during the preparation (drying) of samples for testing. Increased availability of alkali cations in the region due to high binding enables easier formation of chloride salt as the boundary conditions are affected [27].

(2) leaching or outwards diffusion of anions are occurring in the surface region during the $\mathrm{Cl}^{-}$ transport phase and that is resulting in a reduction of $\mathrm{pH}$ approximately up to $10 \mathrm{~mm}$ depth from surface. As more chloride ions ingress into concrete, it is likely that the charge balance is managed by the outwards movement of other anions. This was also evident in activated GGBS system [26] to a depth of 5-12 $\mathrm{mm}$ from surface. Blended system reported in this article have a significantly higher diffusivity 
of the order 10-30 times higher than AA-GGBS, yet the affected region is only $10 \mathrm{~mm}$ based on results in figure 14. This suggests two possibilities: i. availability of anions is less in comparison with AA GGBS and ii. anions may not release as readily from the bound compounds in comparison with AA GGBS.

(3) for AA GGBS concrete reported in [26], there was a skin effect indicated by a localised increase in the total chloride concentration near to the surface regions $5-12 \mathrm{~mm}$. There is no such skin effect visible in the results in figure 14. Reduction in calcium ions closer to the surface due to outwards leaching is possibly one reason for the occurrence of skin effect. Carbonation may also lead to a similar outcome as calcium ions converted into calcite, but that is unlikely in a wet sample subjected to ponding test. Lack of availability of calcium ions is highly likely the reason for the absence of such skin effect.

(4) it is evident from Figure 14 that the total chloride concentration is almost entirely represented by the water-soluble chlorides. The main reaction product in AA-GGBS/FA concrete is a Na-Al silicate hydrate (N-A-S-H) gel which it seems to have no tendency to bind chlorides in the alkalinity range observed in the ponding test conducted on mixes 13-16. It is possible that the water soluble method applied in this research to determine chloride concentration is destabilizing the physically adsorbed chloride ions. Further research is required to characterize the physically absorbed and free chloride ions in the pore solution, in light of the fact that others have reported higher binding capacity for AA FA [25]. The chemical reaction is known to be faster in fresh concrete when introduced alongside the mixing water [26] compared to that in long term chloride exposure tests, therefore further research should also seek to differentiate this effect in binding capacity.

\section{Conclusion}

The engineering and durability properties of activated systems with a GGBS and Fly Ash precursor were presented in this article. Results show that the more GGBS in the blended systems, higher will be the strength and resistance to chloride ingress. Activated system with a GGBS/FA ratio less than 2.5 are not suitable for chloride exposure environments if reinforcing steel is preferred. If the GGBS/FA ratio is between 2.5 and 4, silica content in the activators should be selected based on Figure 13 to have concrete with low diffusivity. More detailed conclusions are given as follows:

1. Results show that it is possible to achieve desirable fresh properties and compressive strength for AA-GGBS/FA concrete when cured at $20^{\circ} \mathrm{C}$. This means such concretes do not require an elevated temperature curing for strength gain. A higher proportion of GGBS results in high early and long-term strength.

2. AA-GGBS/FA concretes with GGBS to Fly Ash ratio less than 4 have moderate to high chloride diffusivity, making them non-viable for protection of reinforcing steel in chloride environments. The blends can be categorised based on the GGBS to fly ash ratio (GGBS/FA) as low diffusivity (GGBS/FA $=80 / 20$ ), high diffusivity $(\mathrm{GGBS} / \mathrm{FA}=60 / 20)$, and very high diffusivity (GGBS/FA $=40 / 60 \& 20 / 80$ ).

3. Chloride concentration was almost entirely represented by the water soluble chlorides in the fly ash dominated AA-GGBS/FA concretes. This indicates either a lack or absence of chemical and physical binding or points towards the stability of bound chlorides in the $\mathrm{pH}$ range $(\leq 11)$ observed in this study.

4. Typically, workable AA-GGBS/FA concretes require binder content of $425 \mathrm{~kg} / \mathrm{m}^{3}$ (GGBS/FA=4) and a water/binder of 0.47 , which is close to the maximum acceptable limit for XD3 and XS3 chloride exposure classes as per BS 8500.

\section{Acknowledgments}


The authors gratefully acknowledge the Engineering and Physical Sciences Research Council for providing financial support for conducting this work [EP/M003272/1]. The authors would like to acknowledge the support provided by Prof. John Provis at The University of Sheffield as PI of the EPSRC project.

\section{References}

[1] J. Whiting, "Manufacture of Cement”, U.S. Patent 544,706, 1895.

[2] A. M. Rashad, Properties of alkali-activated fly ash concrete blend with slag, Iran Journal of Material Science and Engineering, 10 (1), 2013, 57-64

[3] S. Aydin, A ternary optimization of mineral additives of alkali activated cement mortars, Constr. Build. Mater. 43 (2013) 131-138

[4] N.K. Lee, H.K. Lee, Setting and mechanical properties of alkali-activated fly ash/slag concrete manufactured at room temperature, Constr. Build. Mater. 47 (2013) 1201-1209

[5] F. Collins, J. Sanjayan, Effect of pore size distribution on drying shrinkage of alkali activated slag concrete, Cem. Concr. Res., 30 (2000) 1401-1406

[6] A.A. Melo Neto, M.A. Cincotto, W. Repette, Drying and autogenous shrinkage of pastes and mortar with activated slag cement, Cem. Concr. Res., 38 (2008) 565-574

[7] Y. Ma, G. Ye, The shrinkage of alkali activated fly ash, Cem.Concr. Res., 368 (2015) 75-82

[8] M. Chi, R. Huang, "Binding mechanism and properties of alkali-activated fly ash/slag mortars", Constr. and Build. Mater. 40 (2013) 291-298

[9] A.F. Abdalqader, F. Jin, A. Al-Tabbaa, Characterisation of reactive magnesia and sodium carbonateactivated fly ash/slag paste blends, Constr.Build. Mater. 93 (2015) 506-513

[10] X. Gao, Q.L. Yu, H.J.H. Brouwers, Assessing the porosity and shrinkage of alkali activated slagfly ash composites designed applying a packing model, Constr. Build. Mater. 119 (2016)175-184

[11] D. M. Roy, W. Jiang, M.R. Silsbee, Chloride diffusion in ordinary, blended, and alkali-activated cement pastes and its relation to other properties, Cem. Concr. Res. 30 (2000) 1879-1884

[12] BS EN 12350-2, 5\&7, Testing fresh concrete-Part 2, 5\&7: Slump test and Flow test and Air content measurement, BSI, London, 2009

[13] BS EN 12390-3, Testing hardened concrete-Part 3: Compressive strength of test specimens, BSI, London, 2009

[14] NT BUILD 443, Concrete, hardened: accelerated chloride penetration, NORDTEST, Espoo, 1995

[15] RILEM TC 178-TMC: Testing and modeling chloride penetration in concrete. Analysis of total chloride content in concrete, recommendation, Mater. Struct. 35 (2002) 583-585

[16] RILEM TC 178-TMC: Testing and modeling chloride penetration in concrete. Analysis of watersoluble chloride content in concrete, recommendation, Mater. Struct. 35 (2002) 586-588

[17] BS 8500-1, Concrete-complementary British Standard to BS EN 206-1—part 1: method of specifying and guidance for the specifier, BSI, London, 2015

[18] D. Bondar, C.J. Lynsdale, N.B. Milestone, N. Hassani, A.A. Ramezanianpour, Effect of type, form, and dosage of activators on strength of alkali-activated natural pozzolans, Cem. Concr. Compos. 33 (2011) 251-260 
[19] D. Bondar, S. Nanukuttan, M. Soutsos, P.A. Muhammed Basheer, J. Provis, Suitability of alkali activated GGBS/Fly ash concrete for chloride environments. in Tagnit-Hamou, A.(eds), The 10th ACI/RILEM International Conference on Cementitious Materials and Alternative Binders for Sustainable Concrete, 2-4 October 2017, Montreal, Canada, 2017, 35.1-35.14

[20] S. Mundra, S.A. Bernal, M. Criado, P. Hlaváček, G. Ebell, S. Reinemann, G.J.G. Gluth, J.L. Provis, Steel corrosion in reinforced alkali-activated materials, RILEM Technical Letters, 2 (2017) 33-39

[21] M.W. Grutzeck, S.Kwan, M. DiCola, Zeolite formation in alkali-activated cementitious systems, Cem. Concr. Res. 34(6) (2004) 949-955 .

[22] X. Ke, S.A. Bernal, J.L. Provis, Uptake of chloride and carbonate by Mg-Al and Ca-Al layered double hydroxides in simulated pore solutions of alkali activated slag cement, Cem. Concr. Res. 100 (2017) 1-13.

[23] X. Ke, S.A. Bernal, O.H. Hussein, J.L. Provis, Chloride binding and mobility in sodium carbonate-activated slag pastes and mortars, Mater. Struct. 50 (2017) \#252.

[24] Ismail I, Bernal SA, Provis JL, Hamdan S, van Deventer JSJ. Drying-induced

changes in the structure of activated pastes. J Mater Sci 2013;48:3566-77.

[25] I. Ismail et al. / Construction and Building Materials 48 (2013) 1187-1201

[26] D. Bondar, Q. Ma, M. Soutsos, M. Basheer, J.L. Provis, S. Nanukuttan, Alkali activated slag concretes designed for a desired slump, strength and chloride diffusivity, Constr. Build. Mater. 190 (2018) 191-199

[27] Ismail I, Bernal SA, Provis JL, Hamdan S., van Deventer JSJ. Modification of phase evolution in alkali activated blast furnace slag by the incorporation of fly ash. Cem Concr Compos; 2013. (submitted for publication).

[25] M. Castellote, C. Andrade, C. Alonso, Chloride-binding isotherms in concrete submitted to nonsteady-state migration experiments, Cem. Concr. Res., 29 (1999) 1799-1806

[26] Y. Jun, S. Yoon, and J. Eun Oh, A Comparison Study for Chloride-Binding Capacity between Alkali-Activated Fly Ash and Slag in the Use of Seawater, Appl. Sci. 7, 971 (2017) 
Table 1: Oxide composition of GGBS \& Fly ash

\begin{tabular}{cccccccc}
\hline precursor & \multicolumn{6}{c}{ Component (mass\% as oxide) } \\
& $\mathrm{SiO}_{2}$ & $\mathrm{Al}_{2} \mathrm{O}_{3}$ & $\mathrm{CaO}$ & $\mathrm{Fe}_{2} \mathrm{O}_{3}$ & $\mathrm{MgO}$ & others & LOI \\
\hline GGBS & 35.7 & 11.2 & 43.9 & 0.3 & 6.5 & 2.09 & 0.31 \\
\hline Fly ash & 46.8 & 22.5 & 2.2 & 9.1 & 1.3 & 14.5 & 3.6 \\
\hline
\end{tabular}

Table 2: Physical properties of GGBS \& Fly ash

\begin{tabular}{|c|c|c|}
\hline Material & GGBS & Fly ash \\
\hline Fineness $\geq 45 \mu \mathrm{m}$ & $7.74 \%$ & $18.39 \%$ \\
\hline Particle density & 2.86 & 2.21 \\
\hline Water absorption & $35.14 \%$ & $27 \%$ \\
\hline
\end{tabular}

Table 3: Physical properties of aggregates

\begin{tabular}{|c|c|c|c|}
\hline Aggregates & $\begin{array}{c}\text { Bulk specific } \\
\text { gravity }\end{array}$ & $\begin{array}{c}\text { Bulk SSD Specific } \\
\text { gravity }\end{array}$ & $\begin{array}{c}\text { Water Absorption } \\
(\%)\end{array}$ \\
\hline Sand (0-4mm) & 2.72 & 2.73 & 0.75 \\
\hline Fine Crushed Agg. (5-10mm) & 2.67 & 2.75 & 3.14 \\
\hline Coarse Crushed Agg. (10-16mm) & 2.60 & 2.67 & 2.60 \\
\hline
\end{tabular}

Table 4: Details of the different mixes and their properties 


\begin{tabular}{|c|c|c|c|c|c|c|c|c|c|}
\hline $\begin{array}{l}\dot{2} \\
\stackrel{x}{\Sigma}\end{array}$ & 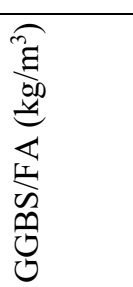 & 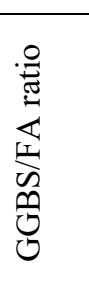 & 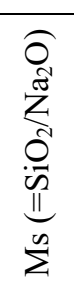 & $\begin{array}{l}\int_{0}^{\circ} \\
0 \\
\mathbb{Z}^{0}\end{array}$ & $\sum_{3}^{n}$ & 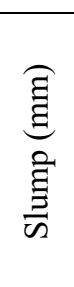 & 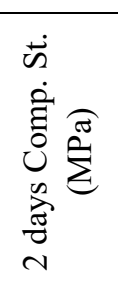 & 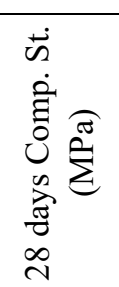 & $\begin{array}{l}\frac{0}{0} \\
\pi \\
0 \\
0 \\
0 \\
0 \\
0 \\
0 \\
0\end{array}$ \\
\hline 1 & $340 / 85$ & 4 & 1.0 & 6 & 0.47 & 170 & $54.6 \pm 3$ & $81.1 \pm 4$ & C65/80 \\
\hline 2 & $340 / 85$ & 4 & 1.25 & 6 & 0.47 & 200 & $51.2 \pm 2$ & $84.8 \pm 4$ & C65/80 \\
\hline 3 & $340 / 85$ & 4 & 0.45 & 8 & 0.47 & 200 & $35.2 \pm 2$ & $60.2 \pm 3$ & $\mathrm{C} 49 / 60$ \\
\hline 4 & $340 / 85$ & 4 & 1.0 & 8 & 0.47 & 230 & $50.9 \pm 2$ & $80.6 \pm 4$ & C65/80 \\
\hline 5 & $255 / 170$ & 1.5 & 1.0 & 6 & 0.46 & 230 & $42.1 \pm 2$ & $73.4 \pm 4$ & C56/70 \\
\hline 6 & $255 / 170$ & 1.5 & 1.25 & 6 & 0.46 & 240 & $40.3 \pm 2$ & $78.5 \pm 4$ & C60/75 \\
\hline 7 & $255 / 170$ & 1.5 & 0.45 & 8 & 0.46 & 205 & $28.8 \pm 1$ & $52.4 \pm 3$ & $\mathrm{C} 40 / 50$ \\
\hline 8 & $255 / 170$ & 1.5 & 1.0 & 8 & 0.46 & 240 & $31.9 \pm 1$ & $75.7 \pm 4$ & C60/75 \\
\hline 9 & $170 / 255$ & 0.67 & 1.0 & 6 & 0.44 & 170 & $28.2 \pm 1$ & $64.8 \pm 3$ & $\mathrm{C} 49 / 60$ \\
\hline 10 & $170 / 255$ & 0.67 & 1.25 & 6 & 0.44 & 210 & $22.3 \pm 1$ & $69.4 \pm 3$ & C52/65 \\
\hline 11 & $170 / 255$ & 0.67 & 0.45 & 8 & 0.44 & 120 & $22.2 \pm 1$ & $54.0 \pm 3$ & $\mathrm{C} 40 / 50$ \\
\hline 12 & $170 / 255$ & 0.67 & 1.0 & 8 & 0.44 & 250 & $23.0 \pm 1$ & $61.2 \pm 3$ & $\mathrm{C} 49 / 60$ \\
\hline 13 & $85 / 340$ & 0.25 & 1.0 & 6 & 0.43 & 225 & $13.8 \pm 1$ & $42.6 \pm 2$ & C32/40 \\
\hline 14 & $85 / 340$ & 0.25 & 1.25 & 6 & 0.43 & 220 & $9.5 \pm 1$ & $47.1 \pm 2$ & $\mathrm{C} 35 / 45$ \\
\hline 15 & $85 / 340$ & 0.25 & 0.45 & 8 & 0.43 & 200 & $9.7 \pm 1$ & $28.4 \pm 1$ & $\mathrm{C} 20 / 25$ \\
\hline 16 & $85 / 340$ & 0.25 & 1.0 & 8 & 0.43 & 250 & $10.4 \pm 1$ & $49.2 \pm 2$ & C35/45 \\
\hline
\end{tabular}

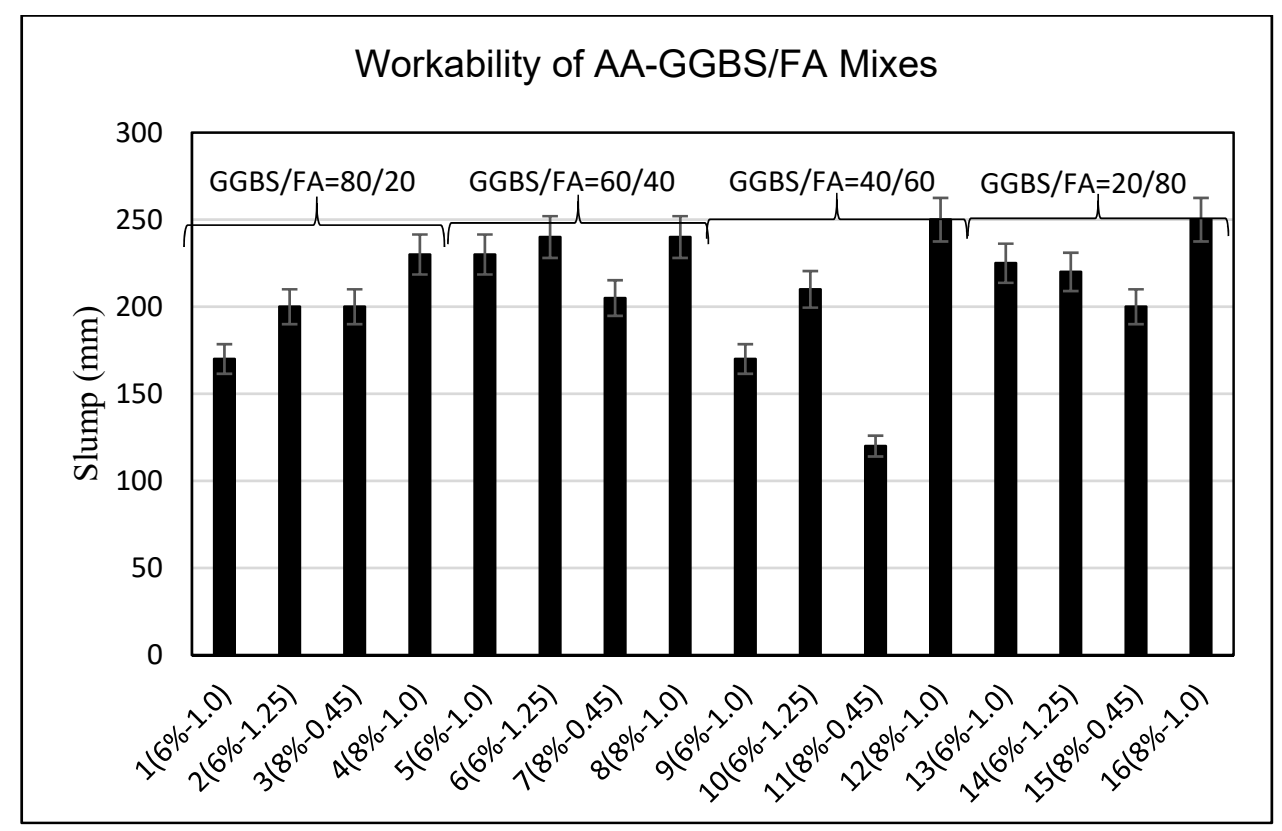

Fig. 1-Slump results of AA-GGBS/FA concretes 


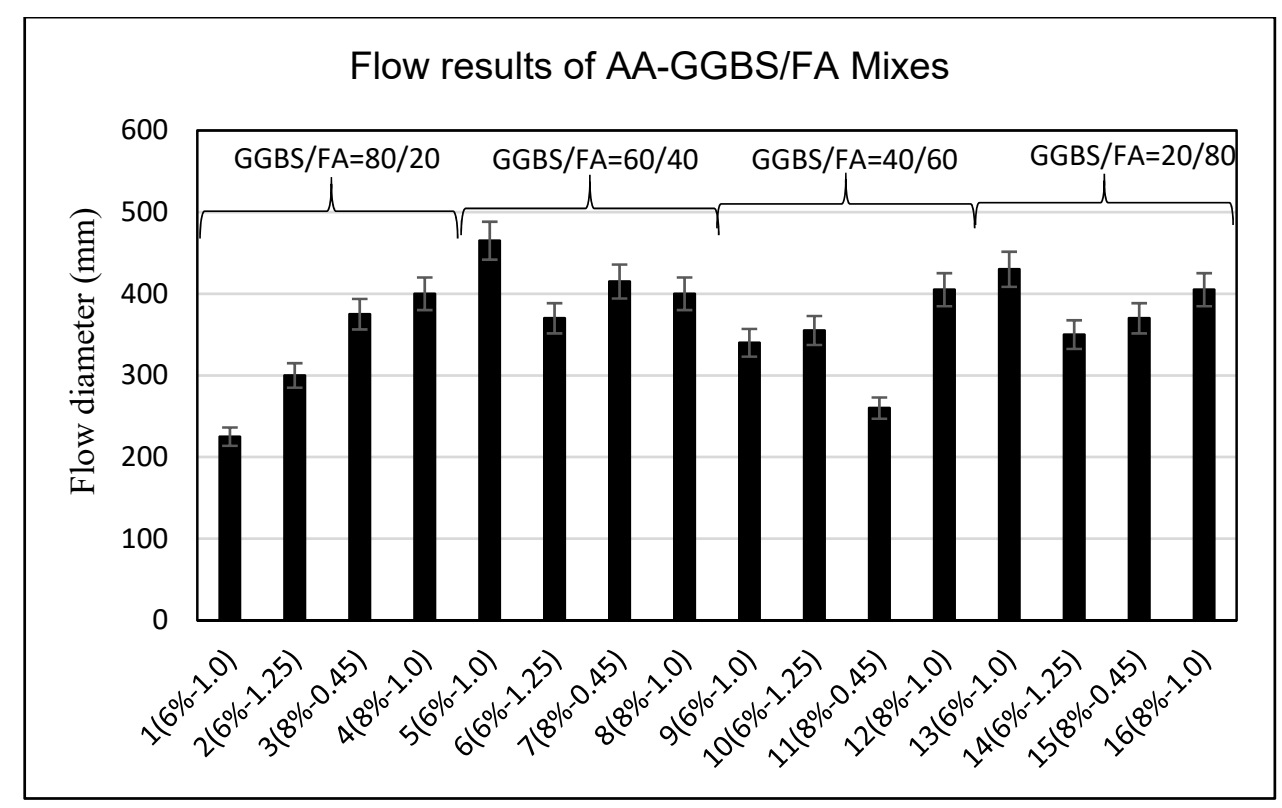

Fig. 2-Flow results of AA-GGBS/FA concretes 


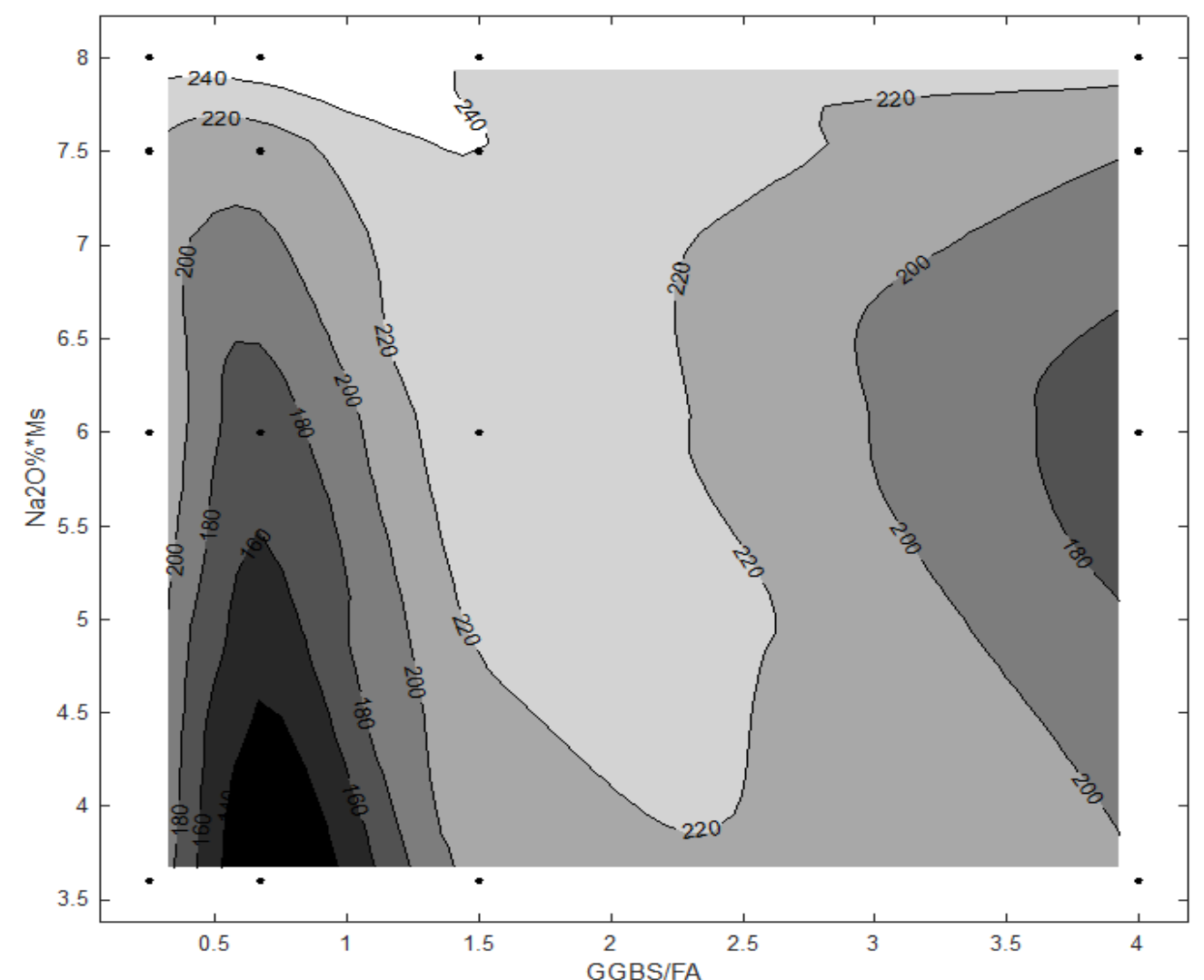

(a)

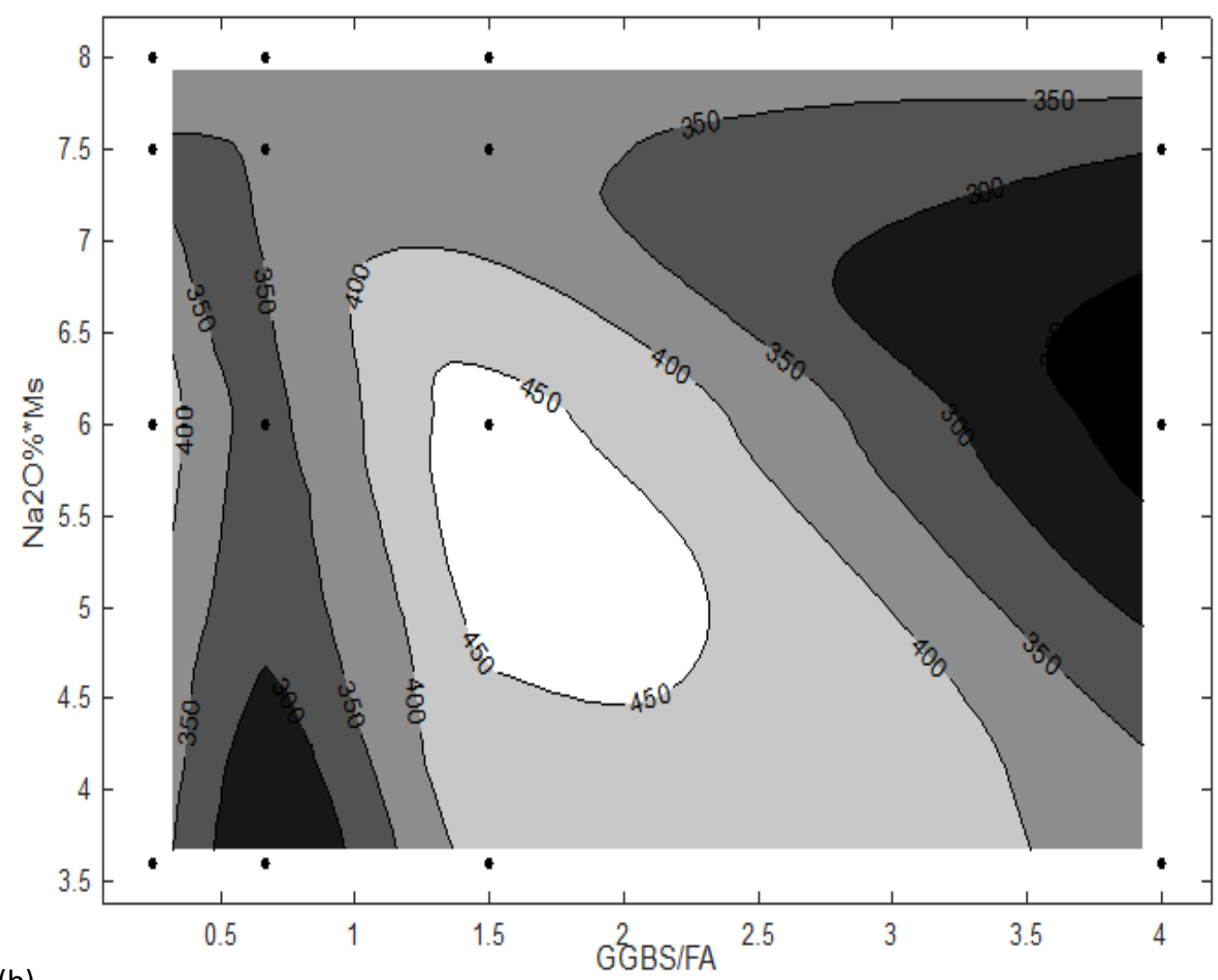

(b)

Fig. 3-Contour graph for workability of AA-GGBS/FA concretes - (a) Slump test, (b) Flow test 


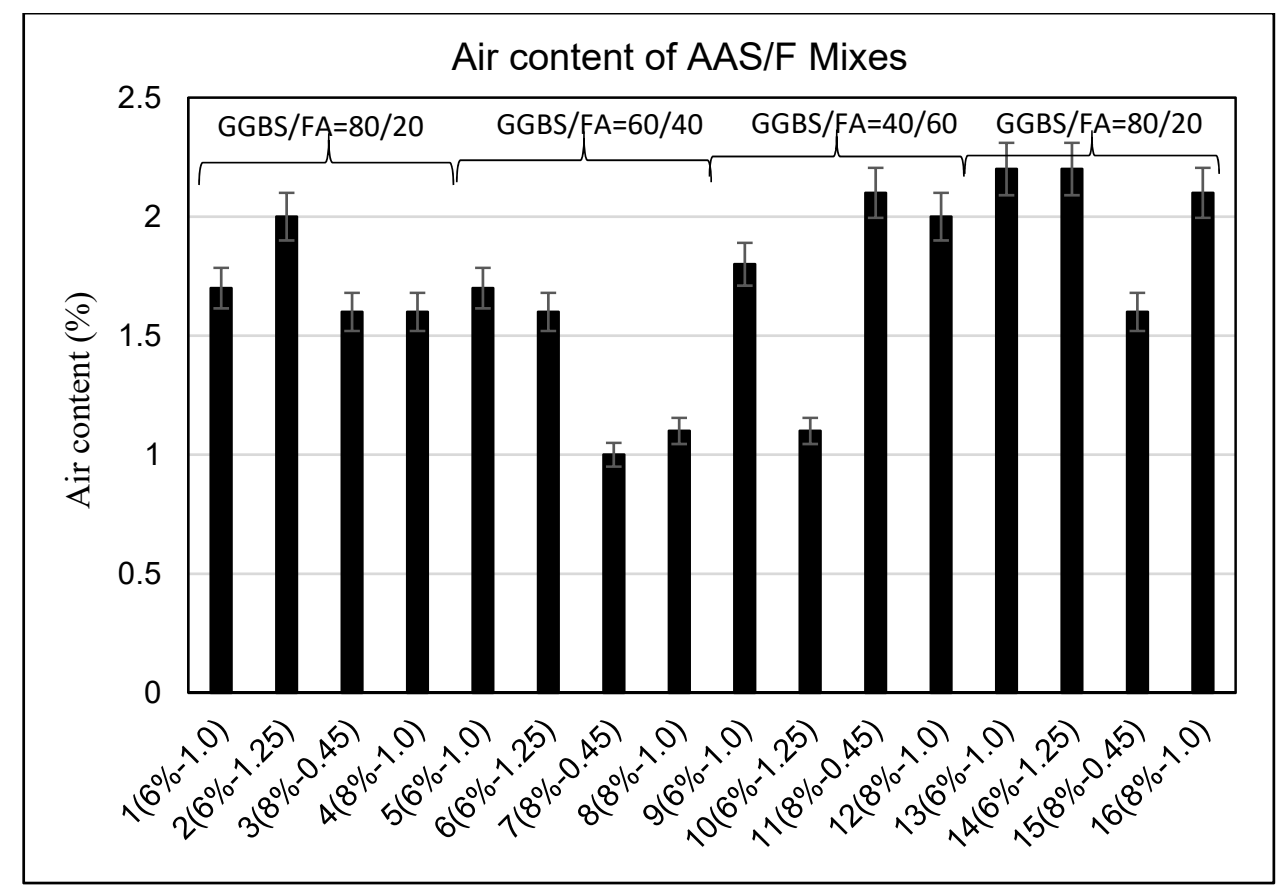

Fig. 4-Air content in fresh mixes of AA-GGBS/FA concretes

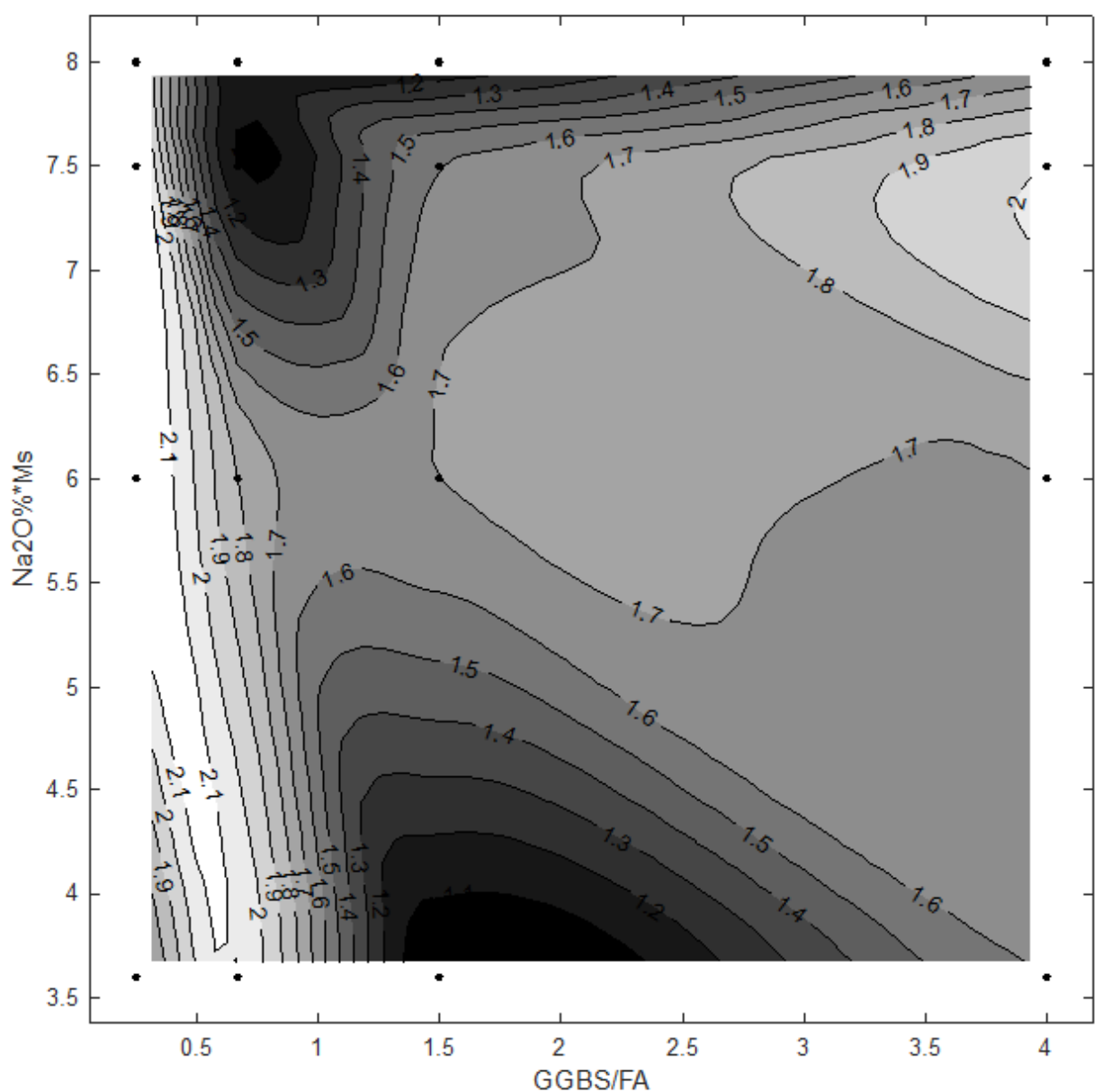

Fig. 5-Contour graph for air content in fresh mixes of AA-GGBS/FA concretes 


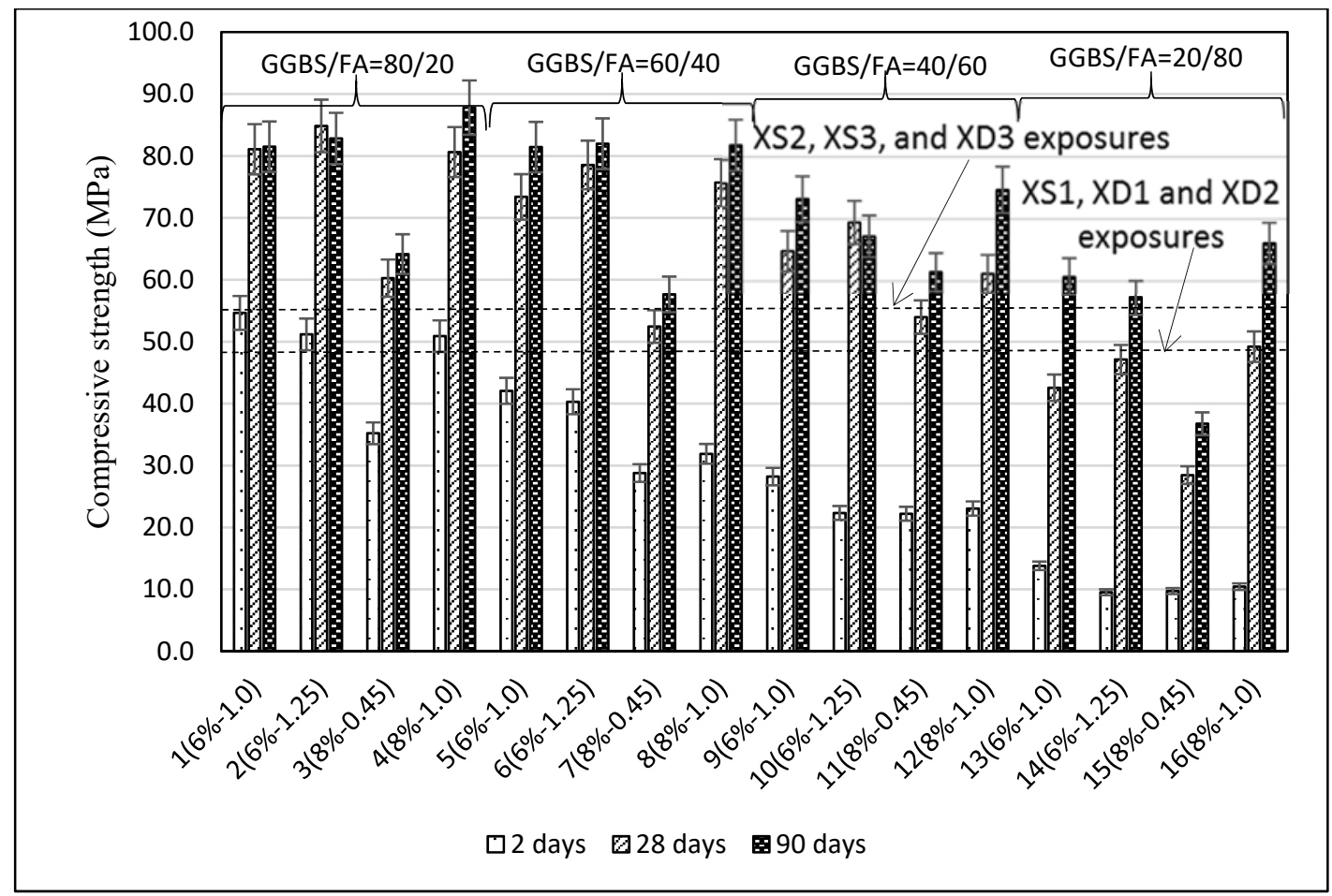

Fig. 6-Compressive strength of AA-GGBS/FA concretes mixes at 2, 28 and 90days

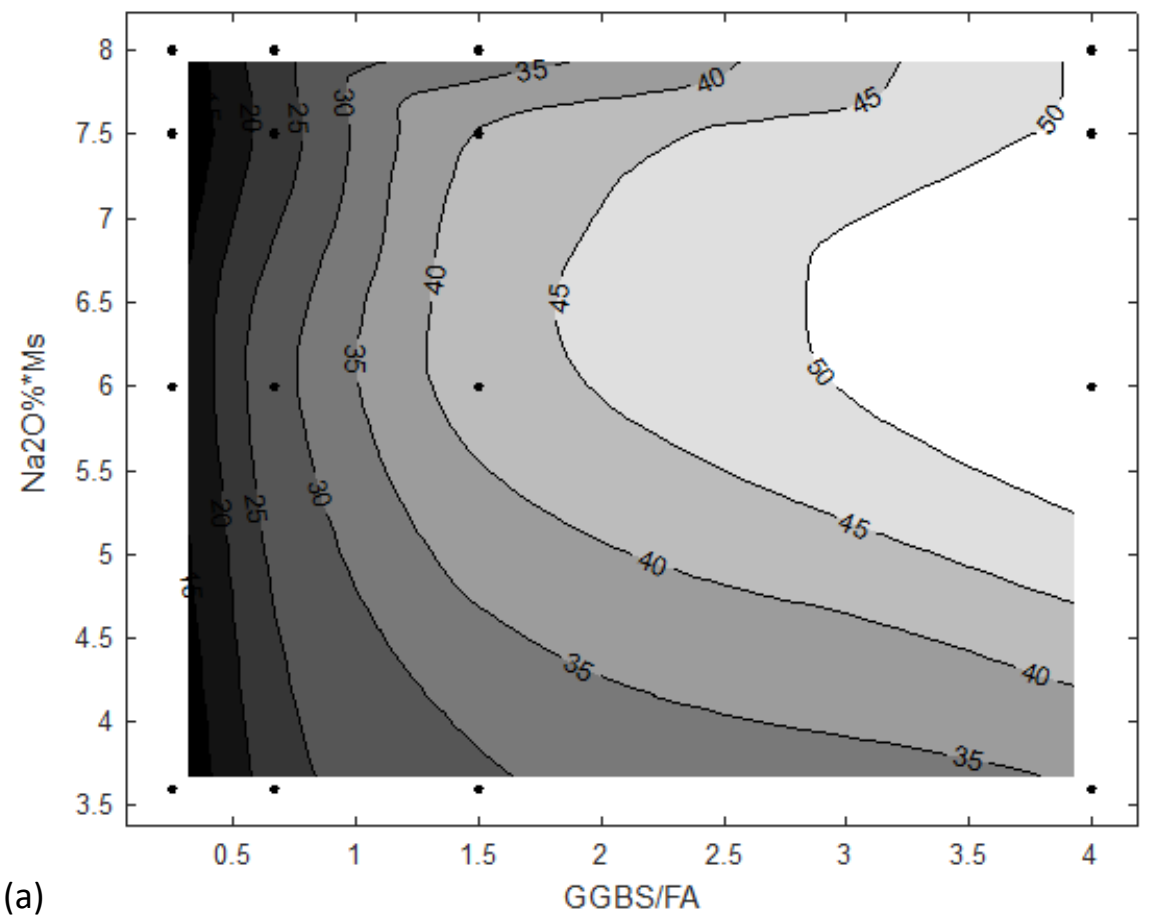



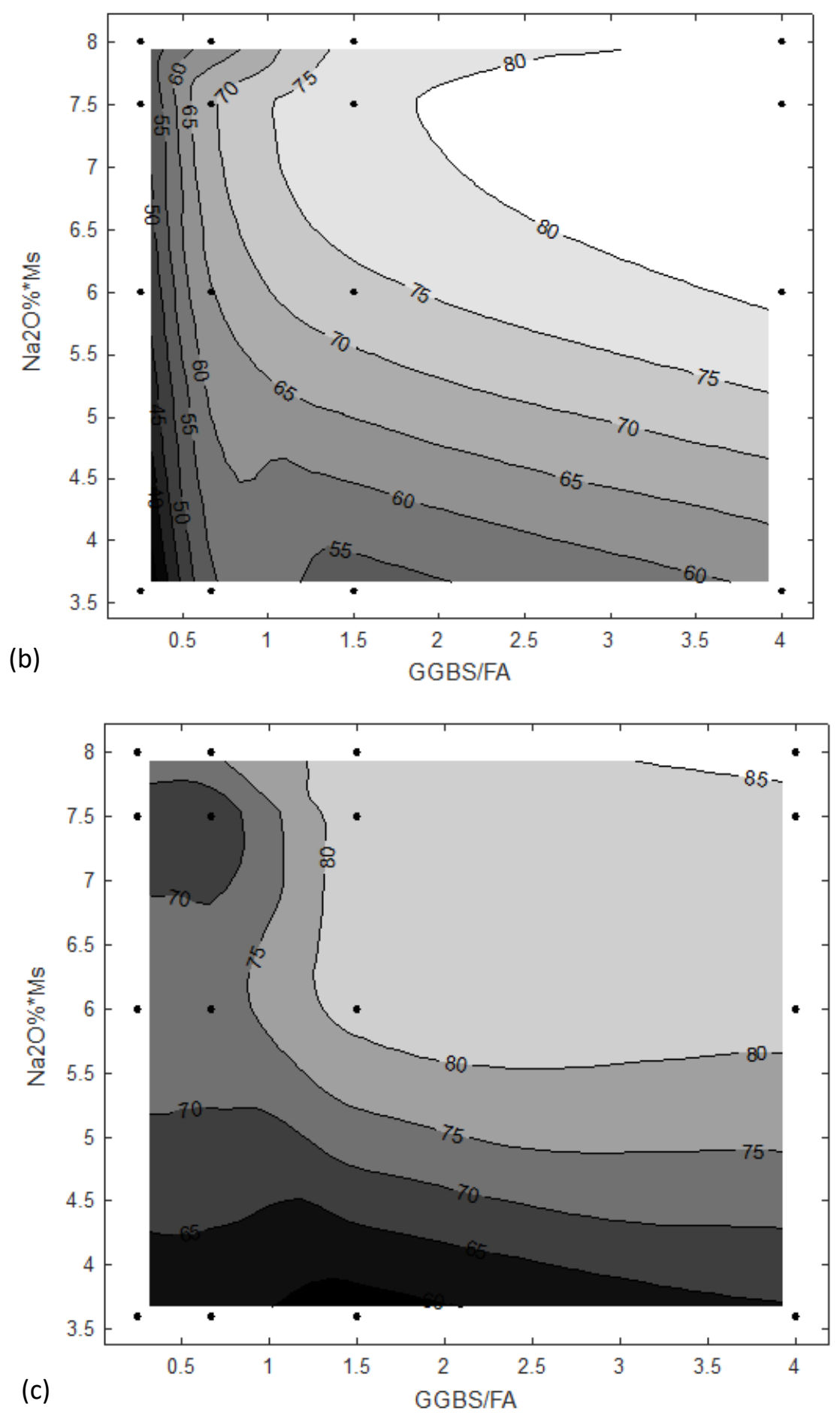

Fig. 7-Contour graph for compressive strength of AA-GGBS/FA concretes

(a) 2days, (b) 28days, (c) 90days 


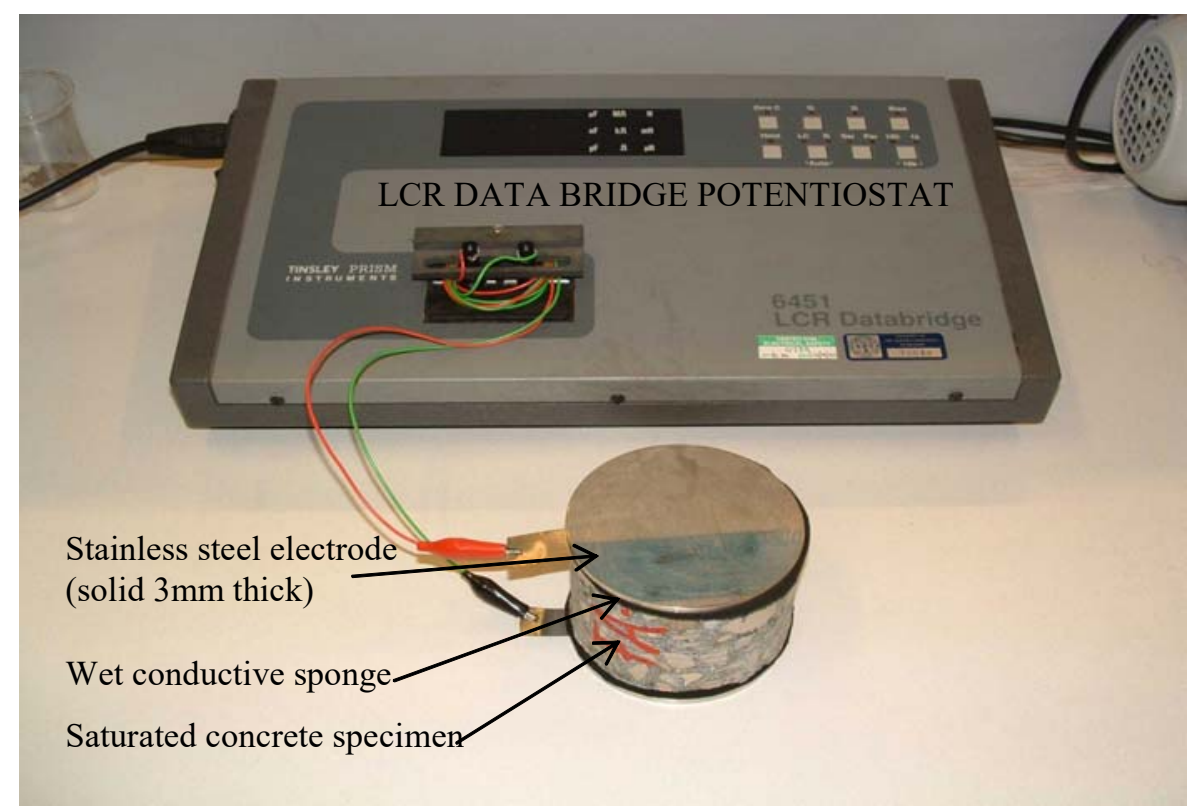

Fig. 8-Bulk resistivity test equipment and sample

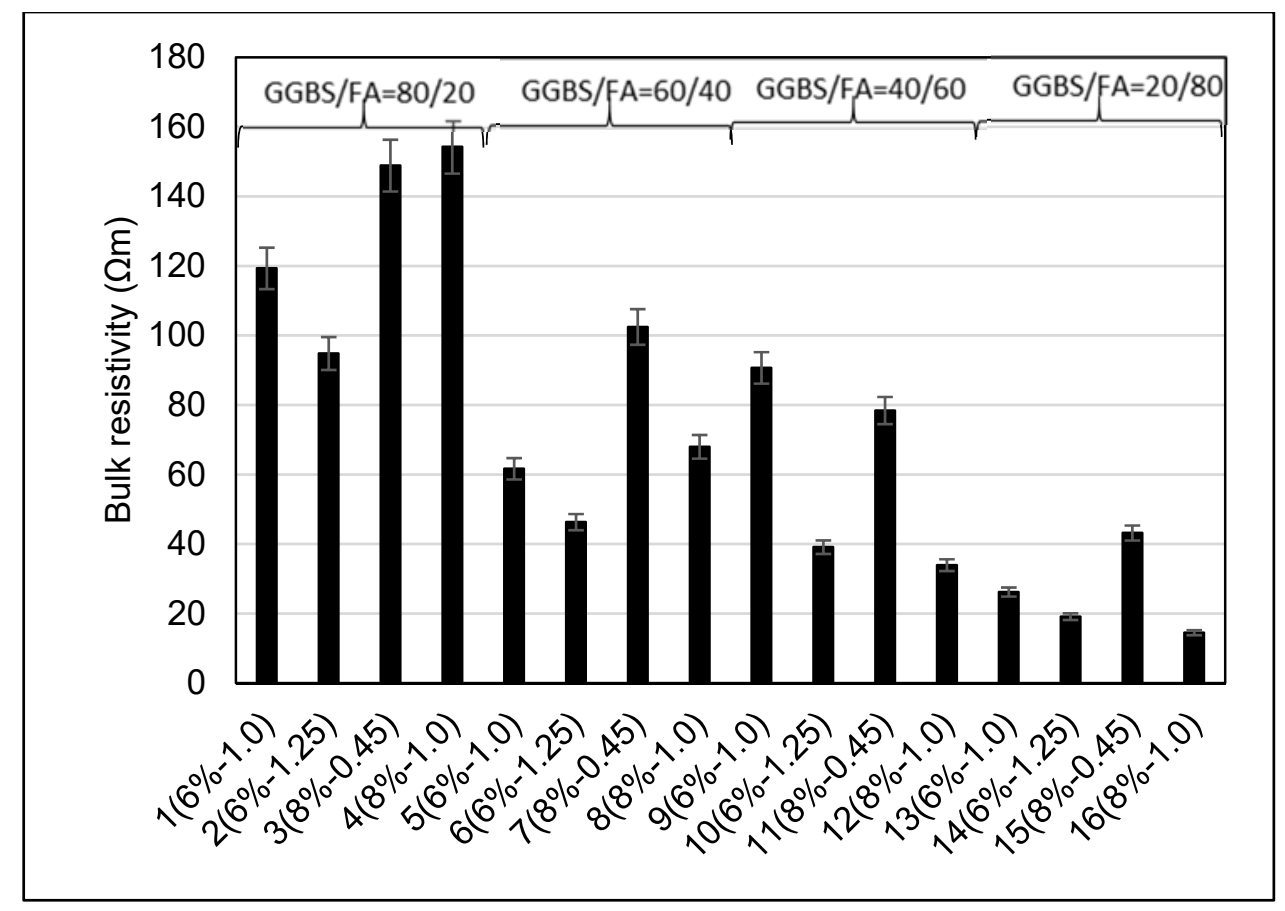

Fig. 9-Bulk resistivity 


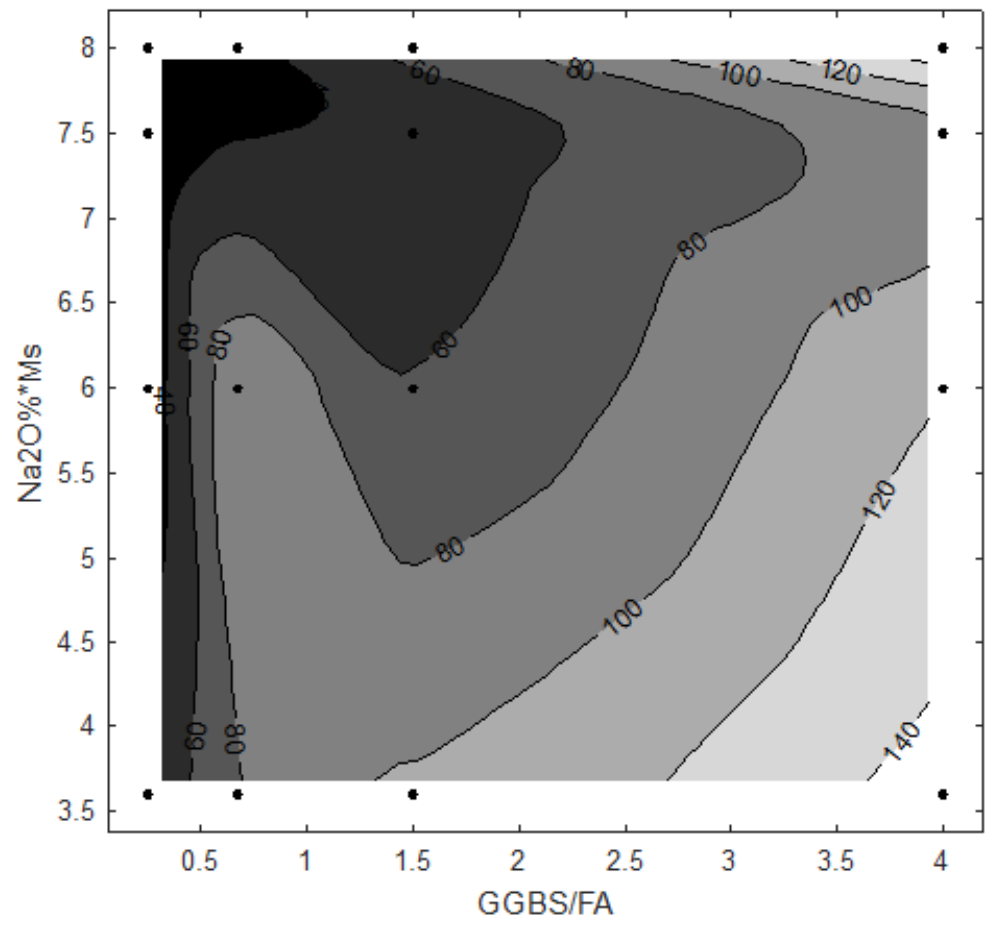

Fig. 10-Contour graph for bulk electrical resistivity $(\Omega . m)$ of AA-GGBS/FA concretes

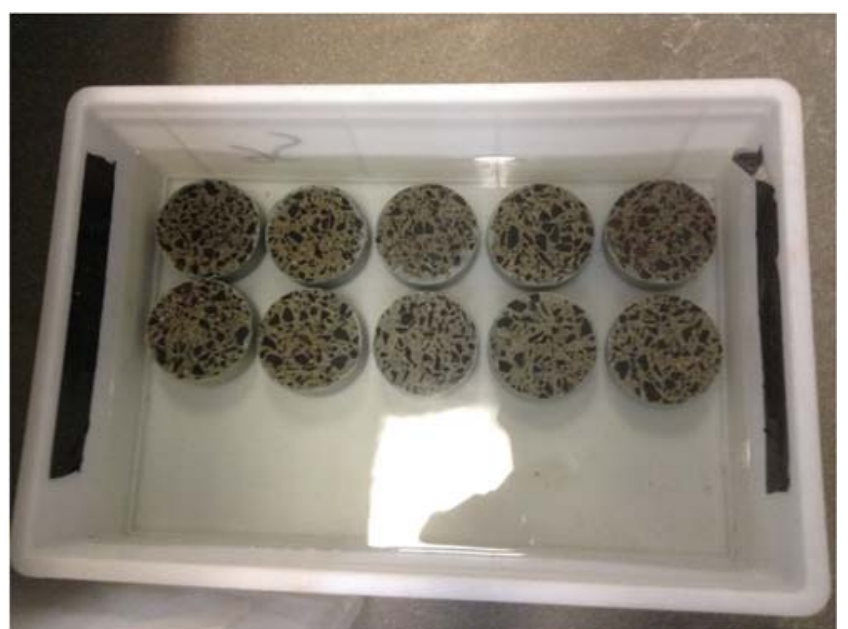

Fig. 11-Concrete sample disks with all surface painted except the top face, placed in an airtight container with sodium chloride solution for diffusion test as per NT Build 443 


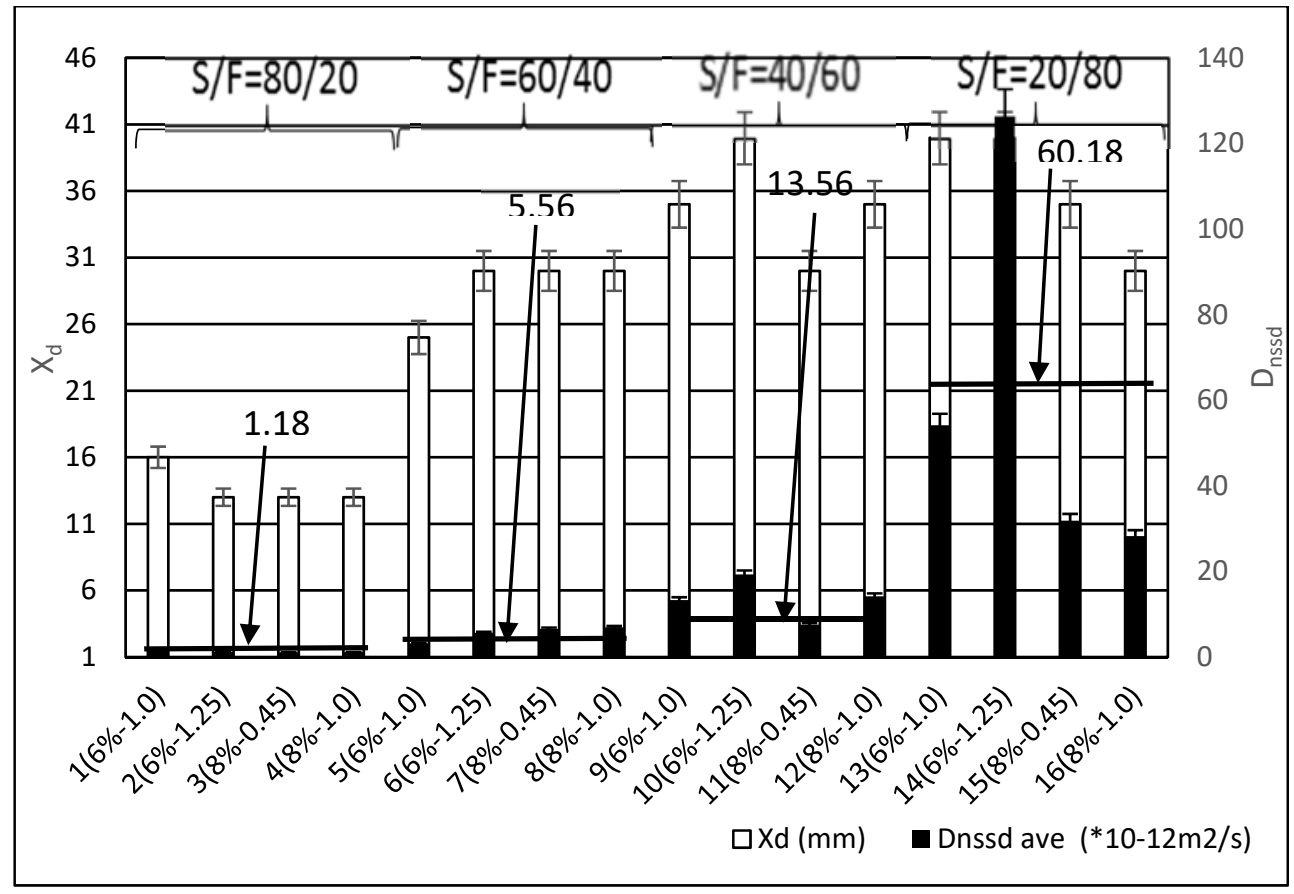

Fig. 12-Chloride penetration depths $\left(\mathrm{X}_{\mathrm{d}}\right)$ and $\mathrm{D}_{\text {nssd }}$ of AA-GGBS/FA concretes

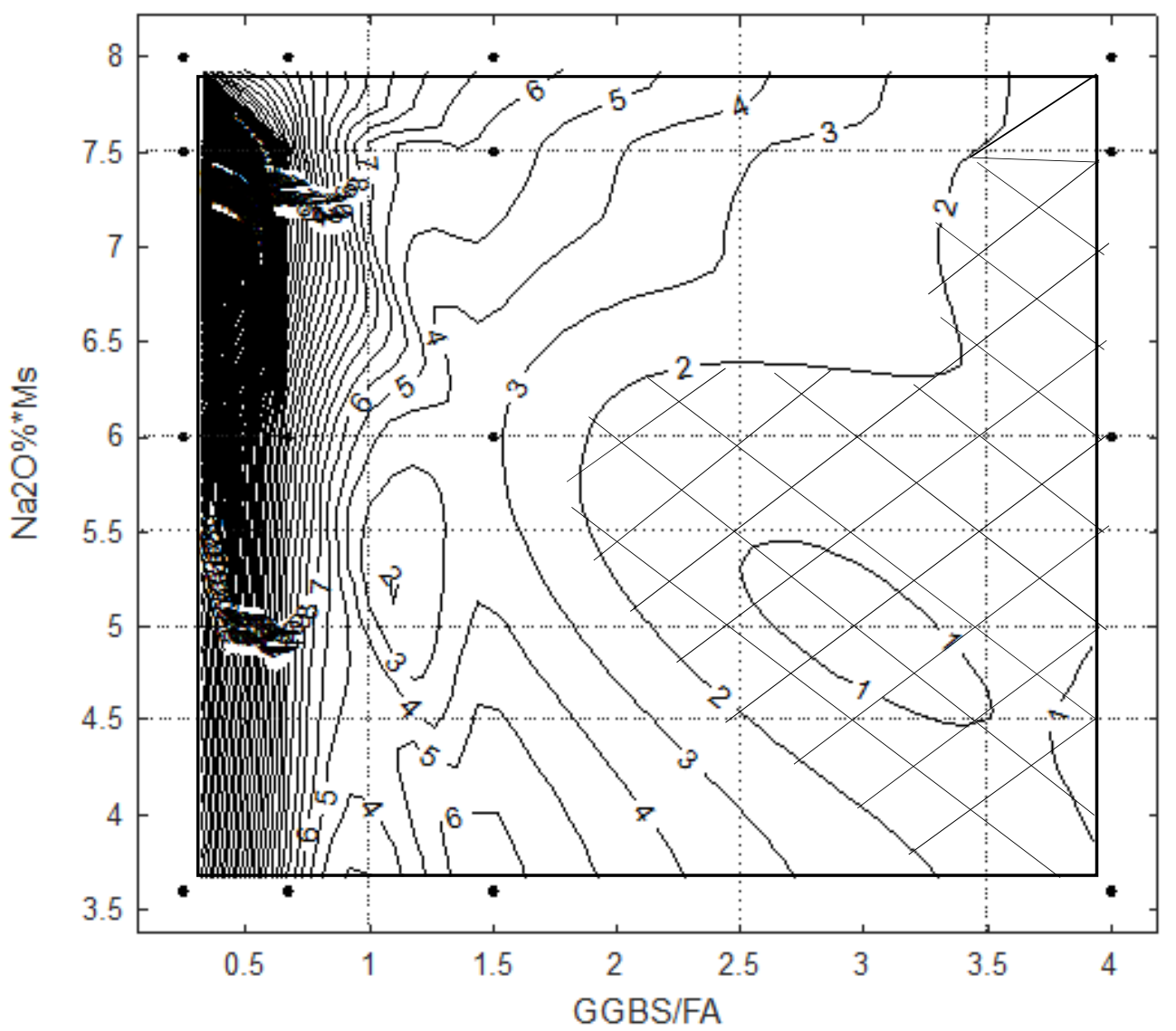

Fig. 13-Contour graph for $\mathrm{D}_{\text {nssd }}\left(\times 10^{-12} \mathrm{~m}^{2} / \mathrm{s}\right)$ of AA-GGBS/FA concretes 


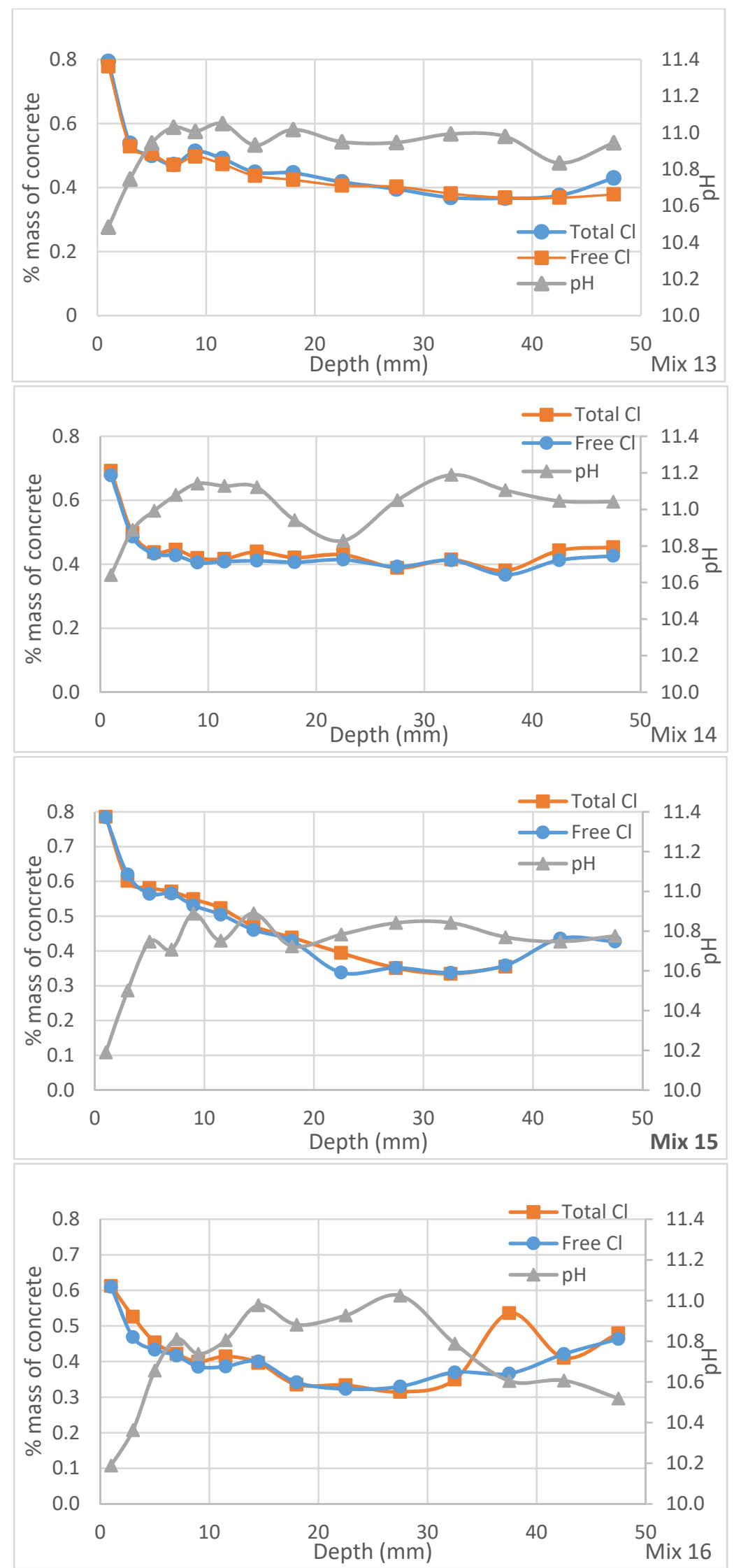

Figure 14 Total and water-soluble chloride concentration and $\mathrm{pH}$ for concrete dust samples collected for NT Build 443 test for mixes 13, 14, 15 and 16 